\title{
Estresse hídrico e massa de sementes na germinação e crescimento de plântulas de Amburana cearensis (Allemão) A.C. Smith ${ }^{1}$
}

\author{
Water stress and seed weight at germination and seedling growth in Amburana \\ cearensis (Allemão) A.C. Smith
}

\author{
João Paulo Nobre de Almeida ${ }^{2 *}$, Charles Lobo Pinheiro ${ }^{3}$, Bruno França da Trindade Lessa ${ }^{3}$, Fernanda Melo \\ Gomes $^{4}$ e Sebastião Medeiros Filho ${ }^{3}$
}

\begin{abstract}
RESUMO - Amburana cearensis, conhecida como cumaru, é uma espécie presente em todo bioma caatinga, sendo recomendada para recuperação de áreas degradadas e usos fitoterápicos. O objetivo do presente trabalho foi determinar os níveis de tolerância ao estresse hídrico na germinação e no crescimento de plântulas de cumaru em função da massa das sementes. Inicialmente as sementes foram pesadas e separadas em três classes (leves, médias e pesadas), sendo estas submetidas ao estresse hídrico, utilizando soluções de Polietilenoglicol 6000 , em diferentes potenciais $(0,0 ;-0,2 ;-0,4 ;-0,6 ;-0,8$ e $-1,0 \mathrm{MPa})$ e colocadas para germinar na temperatura de $30{ }^{\circ} \mathrm{C}$ em câmaras de germinação. $\mathrm{O}$ delineamento experimental foi inteiramente casualizado em esquema fatorial 3 x 6 (classes de massa x potencial hídrico). Para a avaliação da germinação, foram determinados a primeira contagem, porcentagem final e índice de velocidade de germinação, enquanto para a avaliação do crescimento das plântulas determinou-se o comprimento e massa seca do epicótilo e do eixo raiz + hipocótilo e a razão parte aérea/raiz. Os dados foram submetidos ao teste de normalidade e quando se apresentaram normais, realizou-se análise de variância, comparação de médias e regressão. O decréscimo do potencial hídrico prejudica a germinação e o crescimento de plântulas oriundas de sementes médias e pesadas em relação às leves, sendo a partir do potencial -0,6 MPa uma condição estritamente limitante na formação de plântulas normais de A. cearensis.
\end{abstract}

Palavras-chave: Cumaru. Germinação. Potencial osmótico.

\begin{abstract}
Amburana cearensis, known locally as Cumaru, is a species found throughout the caatinga biome, being recommended in the reclamation of degraded areas and for use in phytotherapy. The aim of the present work was to determine the levels of tolerance to water stress at germination and on seedling growth in seedlings of the cumaru, as a function of seed weight. The seeds were initially weighed and separated into three classes (light, medium and heavy), then subjected to water stress using solutions of polyethylene glycol 6000 at different potentials $(0.0,-0.2,-0.4,-0.6,-0.8$ and $-1.0 \mathrm{MPa})$ and left to germinate at $30{ }^{\circ} \mathrm{C}$ in germination chambers. The experimental design was a completely randomised $3 \times 6$ factorial scheme (weight class $\mathrm{x}$ water potential). To evaluate germination, first count, final percentage and rate of germination index were determined, while to evaluate seedling growth, the length and dry weight of the epicotyl and of the root axis plus hypocotyl, and the shoot to root ratio were all determined. Data were tested for normality, and if normal, variance analysis, means comparison and regression were carried out. A decrease in water potential impairs the germination and growth of seedlings derived from medium and heavy seeds in relation to light seeds, with potentials of $-0.6 \mathrm{MPa}$ or more strictly limiting the formation of normal seedlings of A. cearensis.
\end{abstract}

Key words: Cumaru. Germination. Osmotic potential.

\footnotetext{
*Autor para correspondência

${ }^{1}$ Recebido para publicação em 05/11/2013; aprovado em 10/06/2014

Parte da Dissertação do Mestrado do primeiro autor, apresentado ao Programa de Pós-Graduação em Fitotecnia/Universidade Federal do Ceará/UFC, Fortaleza-CE

${ }^{2}$ Departamento de Fitotecnia, Universidade Federal Rural do Semi-Árido, Av. Francisco Mota, 572, Mossoró-RN, Brasil, 59.625-900, joaopaulonobre@yahoo.com.br

${ }^{3}$ Departamento de Fitotecnia, Centro de Ciências Agrárias, Universidade Federal do Ceará, Av. Mister Hull, s/n, Campus do Pici, Fortaleza-CE, Brasil,60.440-900, charlesclp@yahoo.com.br, brunoftl@yahoo.com.br, filho@ufc.br

${ }^{4}$ Programa de Pós-Graduação em Ecologia e Recursos Naturais, Universidade Federal do Ceará, Av. Mister Hull, s/n, Campus do Pici, Fortaleza-CE, Brasil, 60.440-900, fermelogomes@ hotmail.com
} 


\section{INTRODUÇÃO}

Amburanacearensis(Allemão)A.C.Smith,também conhecida popularmente como cumaru, cumaru-de-cheiro ou cerejeira, ocorre com frequência em todo bioma caatinga e possui importância para diversos setores das ciências agrárias, o que torna esta espécie um ponto chave para estudos socioambientais no semiárido nordestino. Quanto à sua aplicabilidade, a madeira é empregada na confecção de mobiliários finos e marcenaria em geral (LORENZI, 2008), além de ser consumida em grande quantidade para a produção industrial de fitoterápicos, em virtude de suas propriedades medicinais cientificamente comprovadas (CANUTO et al., 2008).

O Semiárido nordestino apresenta grandes potencialidades econômicas de desenvolvimento sustentável, constituindo-se em bioma rico e diversificado (ALVES et al., 2012). Porém, em relação às condições climáticas, a escassez de água é um dos fatores mais adversos que limitam o desenvolvimento de muitas espécies, o que fizeram com que as plantas da Caatinga desenvolvessem adaptações físicas e fisiológicas para sua sobrevivência. $\mathrm{O}$ cumaru é um exemplo de espécie pouco sensível à variação do conteúdo de água do solo e que, para isto, esta e outras espécies nativas da caatinga, desencadeiem muitas medidas funcionais para sobreviver em condições de estresse hídrico (TROVÃO et al., 2007).

A água é um dos fatores abióticos que afetam o processo germinativo das sementes (STEFANELLO et al., 2006). Os estudos relacionados com a resposta germinativa de sementes à condição de estresses artificiais têm importância para a ecofisiologia e constituem-se em ferramentas que possibilitam a avaliação dos limites e tolerância de sobrevivência e adaptação destas espécies às condições de estresses naturais (GUEDES et al., 2013).

Uma das técnicas mais utilizadas para simular condições de baixa umidade no substrato tem sido o uso de soluções com diferentes potenciais osmóticos (TAYLOR; HARMAN, 1990). Potenciais hídricos mais negativos no meio reduzem o fluxo de água para a célula, até o ponto extremo no qual a difusão de água através do simplasto cessa e o processo de germinação é diretamente afetado (SOUZA; CARDOSO, 2000).

Atualmente, o polietilenoglicol (PEG) vem sendo utilizado com sucesso em trabalhos de pesquisa para simular os efeitos do déficit hídrico em espécies florestais (AZERÊDO, 2009; GUEDES et al., 2013; PELEGRINI et al., 2013; REGO et al., 2011), uma vez que é quimicamente inerte e atóxico para as sementes, além de não penetrar no tegumento devido ao elevado tamanho de suas moléculas, proporcionando a embebição lenta e controlada das sementes (VILLELA; DONI FILHO; SIQUEIRA, 1991).
A massa da semente e/ou tamanho é um fator que pode estar relacionado como uma estratégia de sobrevivência ao estresse hídrico. Com o aumento no tamanho da semente, a relação entre a superfície e o volume da semente é reduzida, resultando na diminuição da capacidade de obtenção de água suficiente para iniciar o processo de germinação, gerando assim, maiores atrasos na germinação e no estabelecimento de plântulas (HARPER; BENTON, 1966). Assim, a classificação das sementes por massa é uma estratégia que pode ser utilizada para uniformização da germinação e desenvolvimento de plântulas, obtendo-se mudas de tamanhos semelhantes e/ ou de maior vigor (CARVALHO; NAKAGAWA, 2012).

Vários trabalhos foram concretizados para conferir a influência da massa/peso da semente na sua germinação e na qualidade fisiológica de diversas espécies vegetais, porém, no que diz respeito às florestais, estudos ainda são bastante escassos, sendo referenciadas algumas espécies, como jatobá-do-cerrado, ipê-roxo, tamboril (LESSA, 2013; PEREIRA et al., 2011; RIBEIRO et al., 2012).

Assim, objetivou-se nesse trabalho determinar os níveis de tolerância ao estresse hídrico na germinação das sementes e no crescimento de plântulas de cumaru em função da massa da semente.

\section{MATERIAL E MÉTODOS}

As sementes de cumaru foram coletadas manualmente de frutos maduros de 20 matrizes, escolhidas ao acaso, no mês de julho de 2012, na Fazenda Experimental Vale do Curu, situada no município de Pentecoste-CE, a $110 \mathrm{~km}$ de Fortaleza.

Os frutos após serem coletados foram encaminhados para o Laboratório de Análise de Sementes da Universidade Federal do Ceará, em Fortaleza-CE, onde as sementes foram beneficiadas manualmente, colocadas para secar à sombra por seis dias e armazenadas em câmara fria com controle de umidade e temperatura até a instalação do experimento.

Uma amostra de 400 sementes foi separada do lote e cada unidade de semente foi pesada individualmente em balança analítica, com precisão $0,0001 \mathrm{~g}$, com o objetivo de dividir a amostra em três classes distintas de acordo com a sua massa, sendo assim, classificadas em: Leves $(<0,25 \mathrm{~g})$, Médias $(0,25-0,35 \mathrm{~g})$ e Pesadas $(>0,35 \mathrm{~g})$. As categorias leves e pesadas foram baseadas no primeiro e terceiro quartil da representação boxplot, enquanto que as médias foram as sementes que ficaram com o peso intermediário (Figura 1). Após a determinação das classes, as sementes de todo o lote foram pesadas individualmente e separadas em suas respectivas classes. 
Figura 1 - Histograma de frequência (A) e boxplot (B) para a distribuição de massa de uma amostra de 400 sementes de cumaru

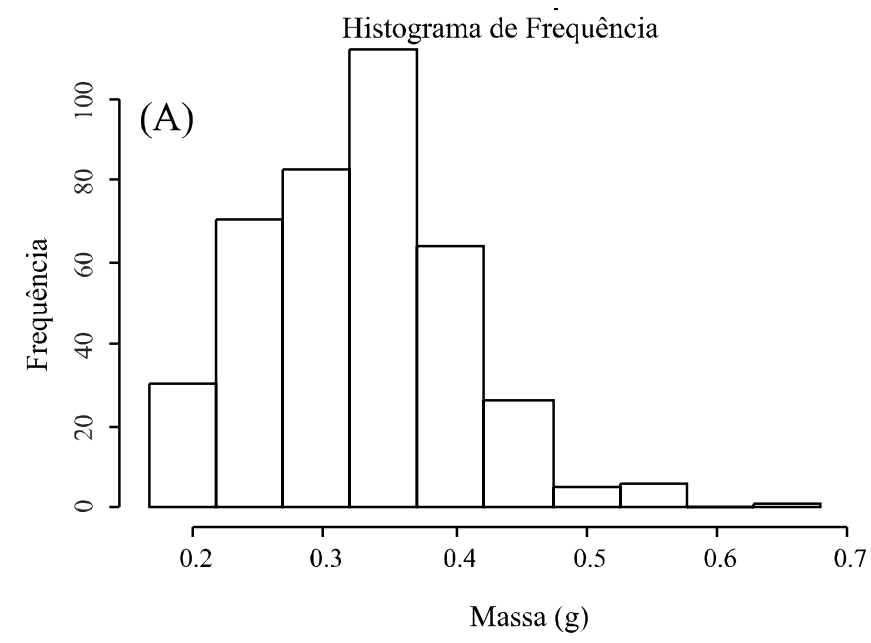

Boxplot

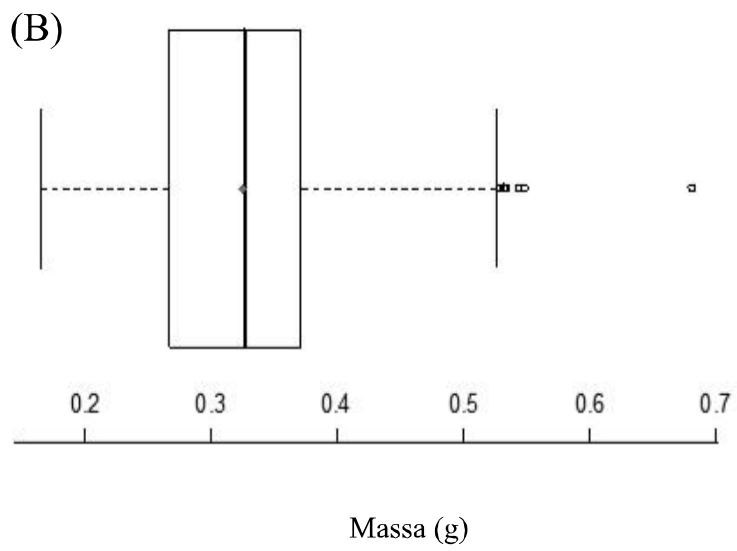

Para a determinação dos teores de água, tomou-se ao acaso duas subamostras de $5 \mathrm{~g}$ de semente de cada classe, sendo posteriormente, acondicionadas em cápsulas de alumínio e levadas à estufa a $105^{\circ} \mathrm{C}$, durante 24 horas (BRASIL, 2009).

A assepsia das sementes de cada classe foi realizada mediante a imersão em hipoclorito de sódio a 5\%, durante 15 minutos e posteriormente lavadas em água corrente e destilada. As mesmas também foram lavadas com uma solução a $0,4 \%$ de nistatina ${ }^{\circledR}$ para evitar o aparecimento de fungos.

As sementes foram submetidas ao estresse hídrico, utilizando soluções de polietilenoglicol (PEG 6000), preparadas de acordo com Villela, Dona Filho, Siqueira (1991). O delineamento experimental utilizado foi inteiramente casualizado em esquema fatorial 3 x 6 (classes de massa $\mathrm{x}$ potenciais hídricos). Para cada classe de massa foram utilizadas quatro repetições com 25 sementes, as quais foram colocadas para germinar em papel toalha e organizado na forma de rolo, umedecidos com água destilada (testemunha) e com solução de PEG 6000 em diferentes potenciais $(-0,2 ;-0,4 ;-0,6 ;-0,8$ e $-1,0 \mathrm{MPa})$, com a quantidade equivalente à 3 vezes o peso do papel. As repetições de cada tratamento foram acondicionadas em sacos plásticos transparentes, com a finalidade de evitar a perda de água por evaporação. O teste de germinação foi conduzido em câmara de germinação regulada na temperatura constante de $30^{\circ} \mathrm{C}$, com fotoperíodo de doze horas. Quando necessário, foi feito o reumedecimento das amostras com a respectiva solução de PEG 6000.

A avaliação da germinação foi diária, sendo consideradas sementes germinadas as que apresentaram extensão radicular igual ou superior a $2 \mathrm{~mm}$ (BORGHETTI; FERREIRA, 2004). Ao final do teste, foram determinadas as porcentagens de germinação (primeira contagem e final, respectivamente aos $7^{\circ}$ e $21^{\circ}$ dia) e o índice de velocidade de germinação (IVG), com contagens diárias do número de sementes germinadas até 21 dias após a semeadura. Após o encerramento do teste de germinação (aos 21 dias), foi avaliado o comprimento das plântulas normais que apresentavam as suas estruturas essenciais bem formadas (BRASIL, 2009) de cada repetição com o auxílio de uma régua graduada em centímetros, sendo mensurada a parte acima da inserção cotiledonar (comprimento do epicótilo - CEP) e abaixo, o eixo raiz + hipocótilo $(\mathrm{CRH})$; os resultados foram expressos em $\mathrm{cm} /$ plântula. O cálculo da relação raiz/parte aérea foi realizado com base nos comprimentos de CEP e CRH. Após a retirada dos cotilédones, todas as frações do epicótilo e hipocótilo + raiz de cada parcela foram colocadas separadamente em sacos de papel tipo kraft e levadas à estufa de ventilação forçada, regulada a $80{ }^{\circ} \mathrm{C}$ durante 24 horas (NAKAGAWA, 1999), para a determinação da massa seca do epicótilo (MSEP) e massa seca da raiz + hipocótilo (MSRH). Decorrido esse período, as plântulas foram colocadas em dessecadores por 10 minutos e, em seguida pesadas em balança analítica $(0,0001 \mathrm{~g})$. O resultado é expresso em g/plântulas. Foi determinada ainda a soma do CEP e CRH, para compor o comprimento total e a massa seca total por plântulas.

Para as análises estatísticas, os dados obtidos foram submetidos ao teste de Shapiro-Wilk e Komolgorov-Smirnov visando analisar a normalidade da distribuição. Quando os dados apresentaram-se normais, em um ou ambos os testes, aplicou-se a análise de variância (ANAVA) e teste de Tukey (5\%), para comparação de médias para os dados qualitativos. Quando significativo, os dados quantitativos foram submetidos à análise de regressão polinomial $(P<0,05)$. O aplicativo Box-Cox foi utilizado para transformar os dados não normais e, atendendo o pressuposto, realizou-se a análise de variância, sendo apresentados os dados originais. 
Quando não atendendo o pressuposto, realizou-se o teste não paramétrico de Wilcoxon-Mann-Whitney (5\%), comparando os tratamentos em pares e de forma independente.

Utilizou-se o auxílio do programa Assistat 7.6 beta para realização da ANAVA e teste de Tukey. Para as análises de regressão, utilizou-se o programa SISVAR 4.3 e o software Action 2.4, para os testes de normalidade e Wilcoxon-Mann-Whitney.

\section{RESULTADOS E DISCUSSÃO}

As sementes de cumaru, no momento da realização dos experimentos, encontravam com teor de água em torno de 9,0\%, independente da massa das mesmas, revelando que o equilíbrio higroscópico das sementes com o ambiente não foi influenciado pelas classes.

A ANAVA (Tabela 1) revelou que houve interação entre as classes de massa de sementes e potenciais hídricos tanto para as variáveis germinativas quanto para os parâmetros de crescimento de plântulas de cumaru, exceto o comprimento total, que atuou de forma isolada. Os dados da porcentagem final de germinação, relação parte aérea com hipocótilo/raiz e massa seca do epicótilo não atenderam à pressuposição de normalidade de distribuição, mesmo após as transformações dos dados.

Observa-se na Figura 2A que as classes de massa das sementes de cumaru influenciaram na porcentagem final de germinação, destacando as sementes leves e médias com os melhores desempenhos. Esses resultados divergem dos relatos de Carvalho e Nakagawa (2012), na qual as sementes de maior massa são as mais nutridas durante seu desenvolvimento, sendo mais vigorosas em função de embriões bem formados e com maiores quantidades de reservas. Essa resposta pode estar relacionada com os tipos de substâncias presentes nas sementes de cumaru, já que Barbosa (2003) menciona que a inibição da germinação dessa espécie pode estar relacionada com os níveis crescentes da substância cumarina nas sementes. Com base nesses estudos, presume-se que a espécie A. cearensis pode apresentar

Tabela 1 - Resumo da ANAVA para as variáveis de germinação e crescimento de plântulas de Amburana cearensis

\begin{tabular}{|c|c|c|c|c|c|c|c|c|}
\hline \multirow{2}{*}{ Fatores de Variação } & \multirow{2}{*}{ GL } & \multicolumn{7}{|c|}{ 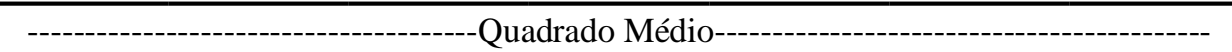 } \\
\hline & & $1^{\mathrm{a}} \mathrm{CONT}$. & IVG & CEP & CHR & CT & MSHR & MST \\
\hline MASSA (M) & 2 & $53,45^{* *}$ & $44,20 * *$ & $6,05 * *$ & $31,18^{* *}$ & $27,50 * *$ & $2,79^{\text {ns }}$ & $4,33 *$ \\
\hline EST. HÍDRICO (E) & 5 & $103,71 * *$ & $61,21 * *$ & $77,51 * *$ & $42,76^{* *}$ & $106,32 * *$ & $23,72 * *$ & $121,57 * *$ \\
\hline MXE & 10 & $3,38 * *$ & $7,70 * *$ & $2,89 *$ & $2,47 *$ & $2,03^{\mathrm{ns}}$ & $5,48 * *$ & $2,39 *$ \\
\hline Tratamentos & 17 & $39,85 * *$ & $28,93 * *$ & $23,89 * *$ & $18,68 * *$ & $35,10 * *$ & $9,97 * *$ & $35,25 * *$ \\
\hline Resíduo & 54 & 1,68 & 0,09 & 0,03 & 0,21 & 0,06 & $1,3 \times 10-4$ & $1,0 \times 10-5$ \\
\hline $\mathrm{CV}(\%)$ & & 18,95 & 38,84 & 49,76 & 29,61 & 23,39 & 40,47 & 21,45 \\
\hline
\end{tabular}

** significância a 1\%, ${ }^{*}$ significância a $5 \%,{ }^{\text {ns }}$ - não significativo, ambos pelo teste F. IVG (índice de velocidade de germinação), CEP (comprimento do epicótilo), CRH (comprimento da raiz + hipocótilo), MSEP (massa seca do epicótilo), MSRH (massa seca da raiz + hipocótilo) e MST (massa seca total)

Figura 2 - Porcentagem de germinação de sementes de A.cearensis em função da massa das sementes (A) e potenciais hídricos (B)
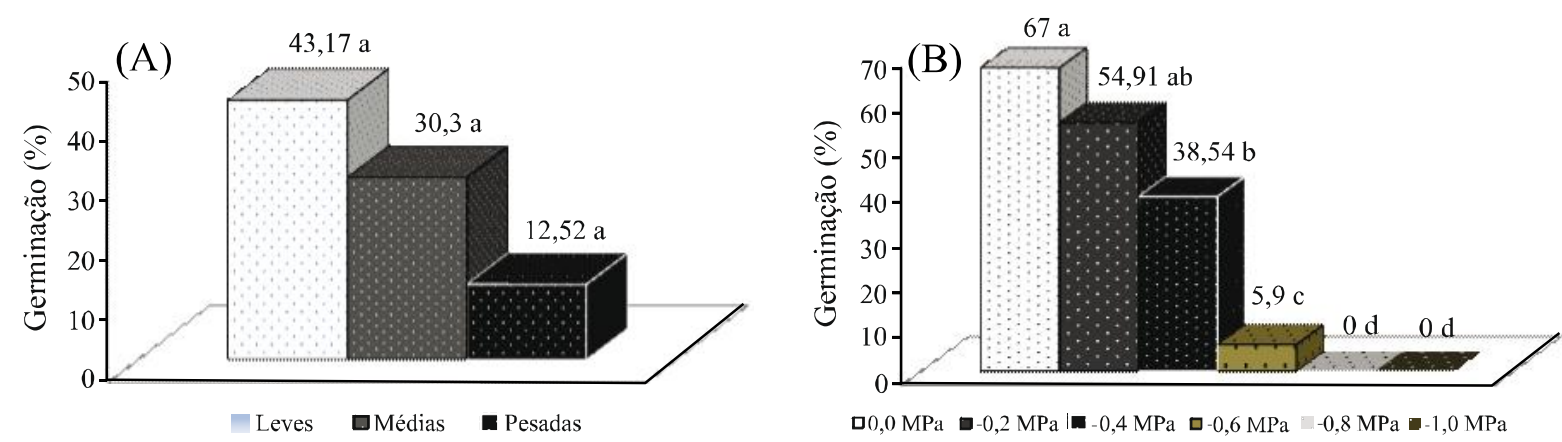

Letras iguais não diferem entre si pelo teste não paramétrico de Mann-Whitney (5\% de probabilidade de erro) 
nas suas sementes de maior massa (>0,35 g), grande quantidades de cumarina que possa vir a inibir a germinação da sua própria espécie.

No que diz respeito ao efeito do estresse hídrico, as melhores médias para a germinação das sementes foram observadas com a testemunha e o potencial - $0,2 \mathrm{MPa}$, onde a partir daí a porcentagem foi influenciada de maneira significativa, verificando-se germinação até o limite de -0,6 MPa, chegando a zero nos potencias - $0,8 \mathrm{e}-1,0 \mathrm{MPa}$ (Figura 2B). Uma possível explicação para esta redução na germinação é o alto peso molecular do PEG, que devido à alta viscosidade e somada à baixa taxa de difusão de $\mathrm{O}_{2}$ pode comprometer a disponibilidade de oxigênio para as sementes durante o processo germinativo (BRACCINI et al., 1996).

O estresse hídrico contribui para a diminuição da percentagem de germinação das sementes, sendo que para cada espécie existe um valor de potencial hídrico no solo, abaixo do qual a germinação não ocorre (ÁVILA et al., 2007). A influência do estresse hídrico analisado com o uso do PEG na germinação de sementes florestais tem sido elemento de diversos estudos com uma ampla faixa de tolerância. Não ocorre germinação de cumaru a -1,2 MPa (BELLO et al., 2008); em sementes de angico-branco, a germinação foi reduzida a partir de -0,6 MPa (REGO et al., 2011); em sementes de corticeira-da-serra, a germinação foi afetada a partir de $-0,5 \mathrm{MPa}$ (PELEGRINI et al., 2013) e em sementes de pau-de-jangada, a germinação reduziu a partir de -0,2 MPa (GUEDES et al., 2013).

$\mathrm{O}$ vigor das sementes de cumaru, determinado pela primeira contagem da germinação, demonstrou que seus maiores percentuais foram obtidos com as sementes leves e médias na ausência do estresse hídrico (Tabela 2). Houve uma redução significativa na germinação com o potencial $-0,6 \mathrm{MPa}$ para as sementes pesadas, -0,8 MPa para as médias e -1,0 MPa para as leves, demonstrando que esta última classe, em condições de elevado estresse hídrico, mesmo em baixa porcentagem, tem condições de germinar mais rápido. Independentemente da classe de massa, quando os potenciais se tornaram mais negativos, houve uma redução considerável na germinação, com inibição a partir do potencial de $-0,6 \mathrm{MPa}$, verificando-se sensibilidade das sementes ao estresse (Figura 3A). Esses resultados são similares aos encontrados por Guedes et al. (2013), que constataram também inibição no vigor sementes de Apeiba tibourbou com o potencial de -0,6 MPa.

Quanto ao maior índice de velocidade de germinação de sementes de cumaru, este foi obtido pelas sementes do tratamento controle (Figura 3B), com valor médio de 4,82 para as sementes leves e 4,71 para as médias, ressaltando que estas classes não diferem entre si, mas diferiram estatisticamente das sementes pesadas (Tabela 2). Ainda na mesma Tabela, uma pequena condição de estresse hídrico (-0,2 MPa) foi responsável pela alteração na velocidade da embebição das sementes, sendo nesse caso, as sementes leves com maior possibilidade em absorver água mais rápido. Conforme vai diminuindo o potencial hídrico, este índice foi reduzido, sendo mais expressivo nas sementes pesadas, que se limitou com o potencial - $0,6 \mathrm{MPa}$, enquanto as leves e médias com o potencial -1,0 MPa.

O estresse hídrico provoca atraso na germinação das sementes e, como as suas respostas são variáveis, a germinação é distribuída no tempo e no espaço permitindo que, em condições naturais, as plântulas encontrem condições ambientais adequadas ao seu estabelecimento e desenvolvimento (BEWLEY; BLACK, 1994). E, neste caso, a massa da semente tornou-se uma estratégia de defesa para sobrevivência em ambientes com restrições hídricas.

Tabela 2 - Valores médios para a primeira contagem da germinação e IVG em função da massa das sementes A. cearensis submetida a diferentes níveis de estresse hídrico

\begin{tabular}{lcccccc}
\hline \multicolumn{7}{c}{ Primeira Contagem $(\%)$} \\
\hline \multicolumn{1}{c}{ Classes } & 0,0 & $-0,2$ & $-0,4$ & $-0,6$ & $-0,8$ & $-1,0$ \\
\hline Leves & $86,00 \mathrm{a}$ & $57,00 \mathrm{a}$ & $31,00 \mathrm{a}$ & $11,00 \mathrm{a}$ & $3,00 \mathrm{a}$ & $0,00 \mathrm{a}$ \\
Médias & $76,00 \mathrm{a}$ & $33,00 \mathrm{~b}$ & $26,00 \mathrm{a}$ & $3,00 \mathrm{~b}$ & $0,00 \mathrm{a}$ & $0,00 \mathrm{a}$ \\
Pesadas & $26,00 \mathrm{~b}$ & $16,00 \mathrm{c}$ & $15,00 \mathrm{~b}$ & $0,00 \mathrm{~b}$ & $0,00 \mathrm{a}$ & $0,00 \mathrm{a}$ \\
\hline \multicolumn{7}{c}{} \\
\hline Leves & $4,82 \mathrm{a}$ & $3,41 \mathrm{a}$ & $2,26 \mathrm{a}$ & $0,57 \mathrm{a}$ & $0,15 \mathrm{a}$ & $0,00 \mathrm{a}$ \\
Médias & $4,71 \mathrm{a}$ & $1,06 \mathrm{c}$ & $1,71 \mathrm{ab}$ & $0,14 \mathrm{a}$ & $0,03 \mathrm{a}$ & $0,00 \mathrm{a}$ \\
Pesadas & $1,81 \mathrm{~b}$ & $2,29 \mathrm{~b}$ & $0,93 \mathrm{~b}$ & $0,00 \mathrm{a}$ & $0,00 \mathrm{a}$ & $0,00 \mathrm{a}$ \\
\hline
\end{tabular}

Letras iguais na coluna não diferem entre si pelo teste de Tukey a 5\% de probabilidade de erro 
Figura 3 - Primeira contagem da germinação (A) e IVG (B) em função da massa das sementes de A. cearensis submetidas a diferentes níveis de estresse hídrico

(A)

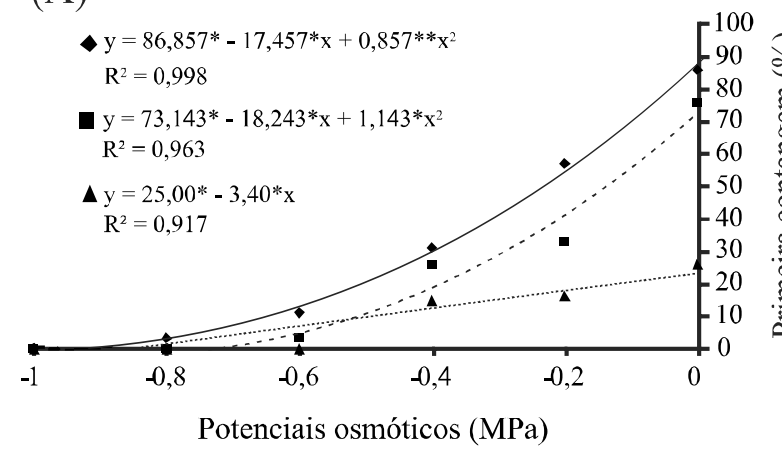

(B)

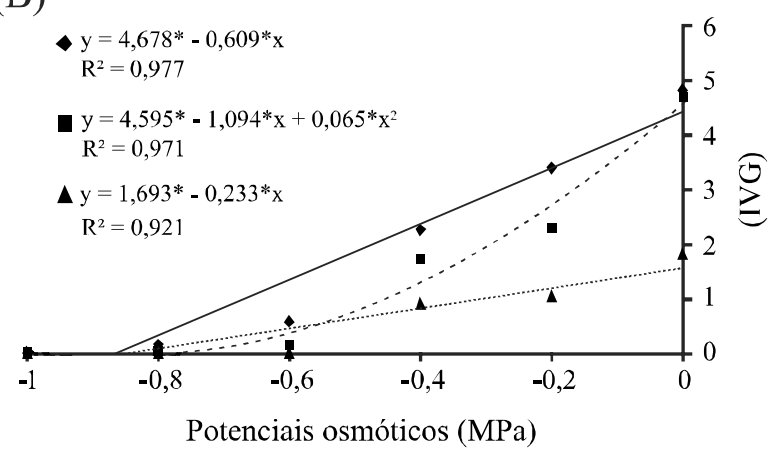

$\bullet$ LEVES MÉDIAS A PESADAS

No geral, em que refere à avaliação germinativa das sementes de cumaru ao longo da redução do potencial hídrico, pode-se observar que as sementes leves foram as que apresentaram maior tolerância às alterações hídricas. De acordo com Marcos Filho (2005), a diminuição da área de contato da semente com o solo acarreta maior dificuldade à captação de água, contribuindo assim, para diminuição da velocidade e percentagem de germinação.

Os resultados seguintes levam em consideração os comportamentos de crescimento de plântulas de cumaru. Observa-se que os comprimentos do epicótilo nas três classes de massa de sementes sofreram redução progressiva com decréscimo do potencial hídrico das soluções a partir do potencial - $0,2 \mathrm{MPa}$, que foi o suficiente para limitar esse crescimento, numa proporção reduzida de $293 \%$ para as sementes leves, $331 \%$ para as médias e $186 \%$ para as pesadas (Figura 4A). Estes resultados são colaborados com os estudos realizados por Bello et al. (2008), revelando que potencial hídrico de -0,2 MPa também já reduze a formação de plântulas normais de A. acreana. A baixa disponibilidade de água, além de limitar a embebição, a velocidade e a percentagem de germinação, reduz o crescimento das plantas, pela diminuição da expansão celular (BEWLEY; BLACK, 1994).

Com as sementes de maior massa, houve formação de plântulas de cumaru até o potencial hídrico de $-0,4$ MPa, onde a partir daí essa massa foi sensível ao estresse (Tabela 3). Já com relação às sementes leves e médias, estas possibilitaram formação de plântulas até o limite de -0,6 MPa, revelando que essas classes de massa são mais tolerantes a um ambiente mais seco em comparação com as pesadas. Para A. acreana houve formação de plântulas normais até -0,8 MPa (BELLO et al., 2008).

No que refere ao crescimento do eixo hipocótilo/ raiz, nota-se que a redução mais severa foi resultante das sementes pesadas (Tabela 3). As sementes leves e médias submetidas ao tratamento controle apresentaram médias semelhantes, não diferindo estatisticamente entre si. Porém, essas médias foram inferiores a quando submetidas ao potencial de - $0,2 \mathrm{MPa}$, observando-se uma maior alocação de reservas para o sistema radicular dessa espécie quando submetida a algum estresse hídrico. Esses resultados são similares aos obtidos por Azerêdo (2009), que também verificou tendência de aumento no comprimento da raiz de plântulas de Piptadenia moniliformis à medida que foi sendo reduzido o potencial hídrico. Este efeito pode ser justificado pelo fato de que as plantas submetidas a condições de déficit hídrico apresentam sistema radicular mais desenvolvido, para favorecer a absorção de água em profundidades de solos mais úmidos (TAIZ; ZEIGER, 2009).

$\mathrm{Na}$ Figura 4B pode-se verificar que, a partir do potencial -0,4 MPa, há uma queda no crescimento radicular das plântulas resultantes de sementes leves e médias, não favorecendo mais a espécie a uma adaptação física radicular. Os potenciais de $-0,8$ e $-1,0 \mathrm{MPa}$ não favoreceram a formação do eixo hipocótilo/raiz, sendo uma condição limitante na formação de plântulas normais.

Observou-se diminuição do comprimento total de plântulas de cumaru à medida que os potenciais hídricos se tornaram mais negativos (Figura 4C), sendo o menor comprimento com o potencial de $-0,6 \mathrm{MPa}$. A disponibilidade de água afeta o crescimento das plantas, por controlar a abertura dos estômatos e a produção de fitomassa (GHOLZ; EWEL; TESKEY, 1990).

As sementes leves e médias diferiram estatisticamente das pesadas quando submetidas ao tratamento controle (Tabela 3). Quando as mesmas passaram para uma condição de estresse hídrico $(-0,2 \mathrm{MPa})$, não houve diferenciação entre as classes de massa. Nesse sentindo, levando em consideração áreas com baixas precipitações pluviométricas, essa característica 
torna-se importante para fins de recomendações para o plantio de espécies capazes de suportar diferentes condições de potenciais osmóticos em diversas situações ecológicas
(REGO et al., 2011), além disso, a massa da semente pode também fornecer respostas de estratégia de sobrevivência frente às condições de restrição de água.

Figura 4 - Comprimento em centímetro do epicótilo (A), hipocótilo+raiz (B) e total (C) de plântulas em função da massa das sementes de A. cearensis submetidas a diferentes níveis de estresse hídrico

- LEVES - MÉdias $\triangle$ PESADAS

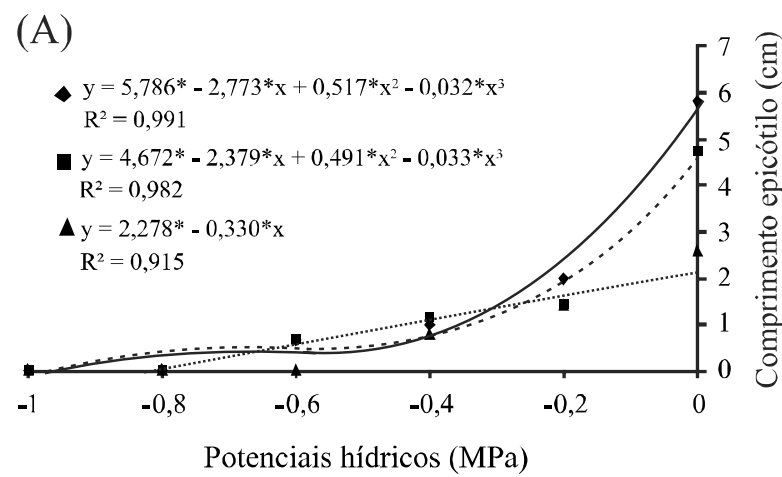

(B)
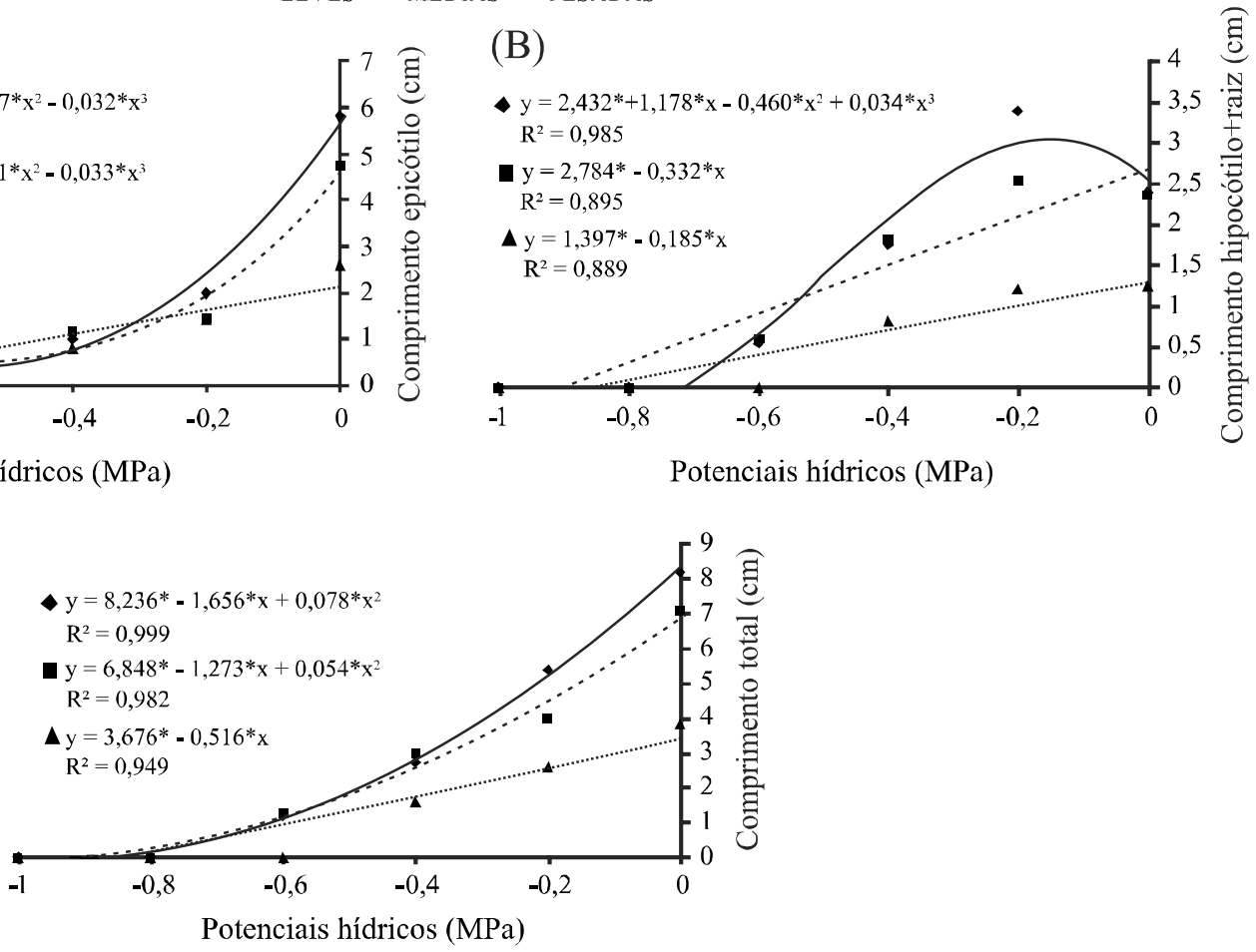

Tabela 3 - Valores médios para o comprimento do epicótilo, hipocótilo+raiz e total de plântulas em função da massa das sementes de A. cearensis submetidos a diferentes níveis de estresse hídrico

\begin{tabular}{|c|c|c|c|c|c|c|}
\hline \multicolumn{7}{|c|}{ Comprimento do epicótilo $(\mathrm{cm})$} \\
\hline \multicolumn{7}{|c|}{ Potenciais Hídricos (MPa) } \\
\hline Classes & 0,0 & $-0,2$ & $-0,4$ & $-0,6$ & $-0,8$ & $-1,0$ \\
\hline Leves & $5,80 \mathrm{a}$ & $1,98 \mathrm{a}$ & $0,97 \mathrm{a}$ & $0,65 \mathrm{a}$ & $0,00 \mathrm{a}$ & $0,00 \mathrm{a}$ \\
\hline Médias & $4,70 \mathrm{a}$ & $1,42 \mathrm{a}$ & $1,16 \mathrm{a}$ & $0,67 \mathrm{a}$ & $0,00 \mathrm{a}$ & $0,00 \mathrm{a}$ \\
\hline Pesadas & $2,60 \mathrm{~b}$ & $1,40 \mathrm{a}$ & $0,78 \mathrm{a}$ & $0,00 \mathrm{a}$ & $0,00 \mathrm{a}$ & $0,00 \mathrm{a}$ \\
\hline \multicolumn{7}{|c|}{ Comprimento do hipocótilo+raiz (cm) } \\
\hline Leves & $2,39 \mathrm{a}$ & $3,38 \mathrm{a}$ & $1,75 \mathrm{a}$ & $0,54 \mathrm{a}$ & $0,00 \mathrm{a}$ & $0,00 \mathrm{a}$ \\
\hline Médias & $2,37 \mathrm{a}$ & $2,52 \mathrm{~b}$ & $1,80 \mathrm{a}$ & $0,60 \mathrm{a}$ & $0,00 \mathrm{a}$ & $0,00 \mathrm{a}$ \\
\hline Pesadas & $1,25 \mathrm{~b}$ & $1,20 \mathrm{c}$ & $0,82 \mathrm{~b}$ & $0,00 \mathrm{a}$ & $0,00 \mathrm{a}$ & $0,00 \mathrm{a}$ \\
\hline \multicolumn{7}{|c|}{ Comprimento total $(\mathrm{cm})$} \\
\hline Leves & $8,18 \mathrm{a}$ & $5,37 \mathrm{a}$ & $2,72 \mathrm{a}$ & $1,18 \mathrm{a}$ & $0,00 \mathrm{a}$ & $0,00 \mathrm{a}$ \\
\hline Médias & $7,08 \mathrm{a}$ & $3,94 \mathrm{a}$ & $2,96 \mathrm{a}$ & $1,27 \mathrm{a}$ & $0,00 \mathrm{a}$ & $0,00 \mathrm{a}$ \\
\hline Pesadas & $3,85 \mathrm{~b}$ & $2,61 \mathrm{a}$ & $1,60 \mathrm{a}$ & $0,00 \mathrm{a}$ & $0,00 \mathrm{a}$ & $0,00 \mathrm{a}$ \\
\hline
\end{tabular}

Letras iguais na coluna não diferem entre si pelo teste de Tukey a $5 \%$ de probabilidade de erro 
A razão raiz/parte aérea foi influenciada pela massa das sementes, sendo as leves e médias com maiores índices em comparação com as sementes pesadas (Figura 5A). Esta resposta é resultado de um maior crescimento das plântulas de cumaru, cuja germinação foi favorecida com as sementes leves e médias.

Quanto ao estresse hídrico, os diferentes níveis de potenciais hídricos, influenciaram na razão raiz/parte aérea de plântulas de cumaru. Nota-se que a partir do potencial -0,2 $\mathrm{MPa}$ houve uma maior alocação de biomassa para raiz em detrimento da parte aérea, estendendo-se até o potencial -0,4 MPa. A partir deste, esta razão foi influenciada pelo estresse hídrico (Figura 5B). Isso indica que, dentro de uma faixa limite de estresse, durante a fase germinativa do cumaru, as raízes tem capacidade de crescer e se alongar mais do que a parte aérea. Essa maior alocação de biomassa para a raiz como resposta à deficiência hídrica é considerado como importante mecanismo de aclimatação à seca.

As respostas adquiridas pela razão R/PA demonstram que as plântulas de cumaru, quando submetidas ao estresse hídrico, respondem a esta condição com formação e expansão dos seus xilopódios, investindo mais no crescimento de suas raízes do que no crescimento da parte aérea, com finalidade de reduzir a perda de água pelas folhas, armazenando assim, mais água nas raízes de reservas para sobreviver longos períodos de escassez de água. Por tratar de espécie da caatinga, de clima bastante seco, as plantas desenvolvem adaptações morfológicas e fisiológicas com finalidade de um melhor aproveitamento e uso de água do solo.

A massa seca do epicótilo das plântulas de cumaru não foi influenciada pela massa da semente. Embora a classe pesada apresentasse baixo comportamento germinativo, as mesmas quando conseguem atingir a fase de plântulas, alcançam o mesmo rendimento de biomassa representada pelas sementes leves e médias (Figura 6A).
Ao contrário do peso das sementes, o conteúdo de massa seca foi influenciado significativamente pelos diferentes potenciais hídricos, havendo uma diminuição expressiva (329\%) com o potencial -0,2 MPa. A partir daí, a diminuição foi mais sutil, não havendo mais formação de biomassa nos potenciais -0,8 e -1,0 MPa (Figura 6B). Estes resultados também são similares aos encontrados por Guedes et al. (2013), que observaram que o conteúdo de massa seca de plântulas de Apeiba tibourbou foi reduzido à medida que restringiu o potencial hídrico, tornando-se nulo a -0,8 MPa. Essa redução na biomassa do epicótilo pode ser explicada pela diminuição no metabolismo das sementes, em função da menor disponibilidade de água para digestão das reservas e translocação de produtos metabolizados (BEWLEY; BLACK, 1994).

A massa seca do eixo hipocótilo+raiz também foi afetada pelos diferentes potenciais hídricos (Figura 7A), porém não foi influenciada pela massa das sementes (Tabela 4). Observou-se que os maiores conteúdos de massa seca foram obtidos com o potencial -0,2 MPa e com o tratamento controle. Com isso, verifica-se que em função da espécie ter investido em um maior crescimento de raiz no potencial -0,2 Mpa resultaram também em maior acúmulo de biomassa radicular. Abaixo desse potencial, fica evidente uma redução na biomassa, principalmente no que refere às sementes de maior massa, sendo o potencial -0,4 MPa o seu limite máximo (Tabela 4). Nesse sentido, os principais mecanismos da planta para resistir às condições de estresse hídrico são o aumento e aprofundamento da raiz, podendo ser pelo crescimento (alongamento celular) ou pelo ganho de massa seca (crescimento e aumento de espessura das paredes celulares) (TÁVORA; MELO, 1991).

No tocante a massa seca total das plântulas de cumaru, observa-se também uma redução linear ao longo do aumento do potencial hídrico (Figura 7B). Observou-se que os maiores conteúdos da massa seca foram obtidos no tratamento controle, onde a partir deste potencial ocorreu limitação da biomassa

Figura 5 - Relação raiz/parte aérea de sementes de A. cearensis em função da massa das sementes (A) e potenciais hídricos (B)

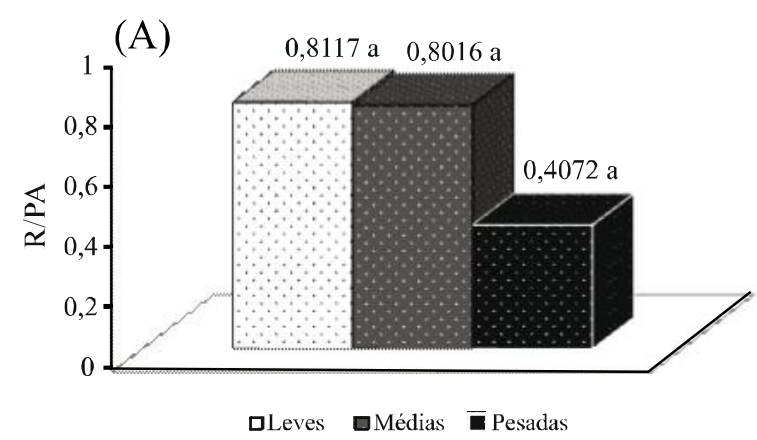

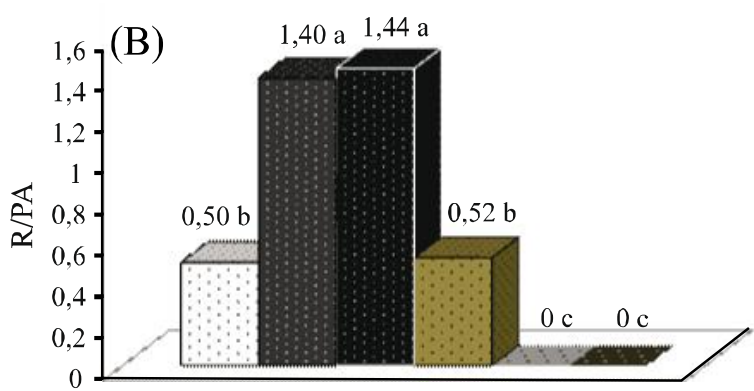

$\square 0,0 \mathrm{MPa} \square-0,2 \mathrm{MPa} \mid-0,4 \mathrm{MPa} \square-0,6 \mathrm{MPa}=-0,8 \mathrm{MPa} \square-1,0 \mathrm{MPa}$

Letras iguais não diferem entre si pelo teste não paramétrico de Mann-Whitney (5\% de probabilidade de erro) 
total até se tornar nulo no potencial hídrico -0,6 MPa para as sementes pesadas e de - $0,8 \mathrm{MPa}$ para as sementes leves e médias (Tabela 4). Esta redução se dá devido à demanda dos processos fisiológicos e biológicos ou pela dificuldade de hidrólise e a mobilização das reservas armazenadas nas sementes (BEWLEY; BLACK, 1994).

Tabela 4 - Valores médios para a massa seca do hipocótilo + raiz e total de plântulas em função da massa de sementes de cumaru (A. cearensis) submetida a diferentes níveis de estresse hídrico

\begin{tabular}{llllllc}
\hline \multicolumn{7}{c}{ Massa seca do hipocótilo + raiz (g plântula $\left.{ }^{-1}\right)$} \\
\hline Classes & 0,0 & $-0,2$ & $-0,4$ & $-0,6$ & $-0,8$ & $-1,0$ \\
\hline Leves & $0,0073 \mathrm{a}$ & $0,0077 \mathrm{a}$ & $0,0049 \mathrm{a}$ & $0,0023 \mathrm{a}$ & $0,00 \mathrm{a}$ & $0,00 \mathrm{a}$ \\
Médias & $0,0078 \mathrm{a}$ & $0,0069 \mathrm{a}$ & $0,0061 \mathrm{a}$ & $0,0012 \mathrm{a}$ & $0,00 \mathrm{a}$ & $0,00 \mathrm{a}$ \\
Pesadas & $0,0063 \mathrm{a}$ & $0,0082 \mathrm{a}$ & $0,0037 \mathrm{a}$ & $0,00 \mathrm{a}$ & $0,00 \mathrm{a}$ & $0,00 \mathrm{a}$ \\
\hline \multicolumn{7}{c}{ Massa seca total $\left(\mathrm{g}\right.$ plântula $\left.{ }^{-1}\right)$} \\
\hline Leves & $0,0231 \mathrm{~b}$ & $0,0165 \mathrm{a}$ & $0,0102 \mathrm{a}$ & $0,0062 \mathrm{a}$ & $0,00 \mathrm{a}$ & $0,00 \mathrm{a}$ \\
Médias & $0,0288 \mathrm{a}$ & $0,0148 \mathrm{a}$ & $0,0133 \mathrm{a}$ & $0,035 \mathrm{ab}$ & $0,00 \mathrm{a}$ & $0,00 \mathrm{a}$ \\
Pesadas & $0,0248 \mathrm{ab}$ & $0,0150 \mathrm{a}$ & $0,0085 \mathrm{a}$ & $0,00 \mathrm{~b}$ & $0,00 \mathrm{a}$ & $0,00 \mathrm{a}$ \\
\hline
\end{tabular}

Letras iguais na coluna não diferem entre si pelo teste de Tukey a $5 \%$ de probabilidade de erro

Figura 6 - Massa seca do epicótilo de plântulas de cumaru em função da massa das sementes (A) e potenciais hídricos (B)
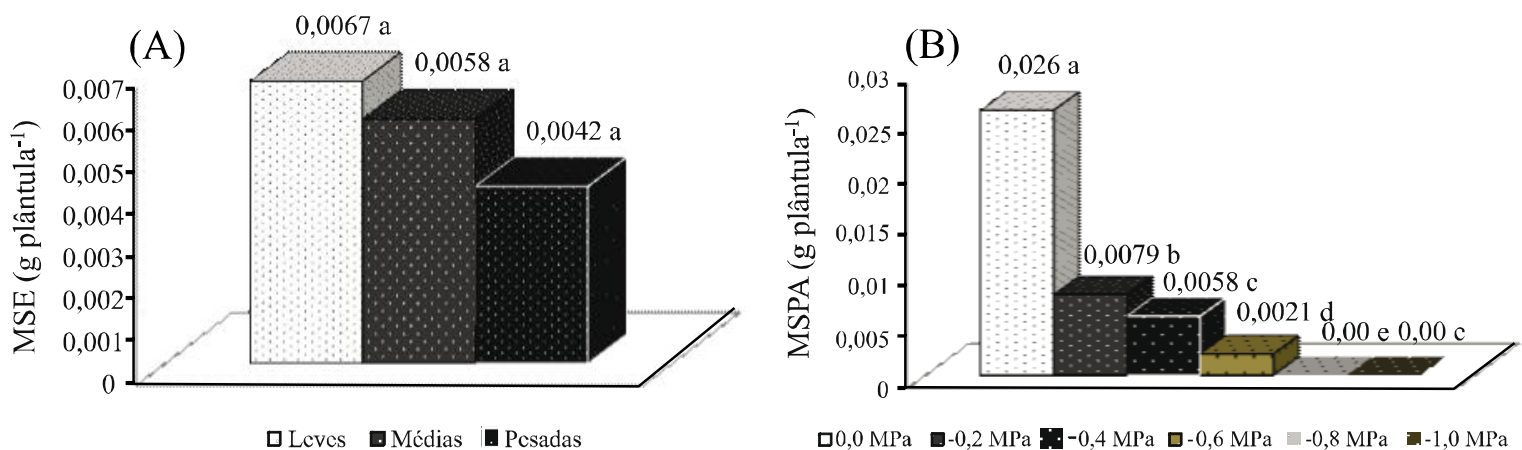

Letras iguais não diferem entre si pelo teste não paramétrico de Mann-Whitney (5\% de probabilidade de erro)

Figura 7 - Massa seca em g plântula ${ }^{-1}$ do hipocótilo+raiz (A) e total (B) função da massa das sementes de A. cearensis submetidas a diferentes níveis de estresse hídrico
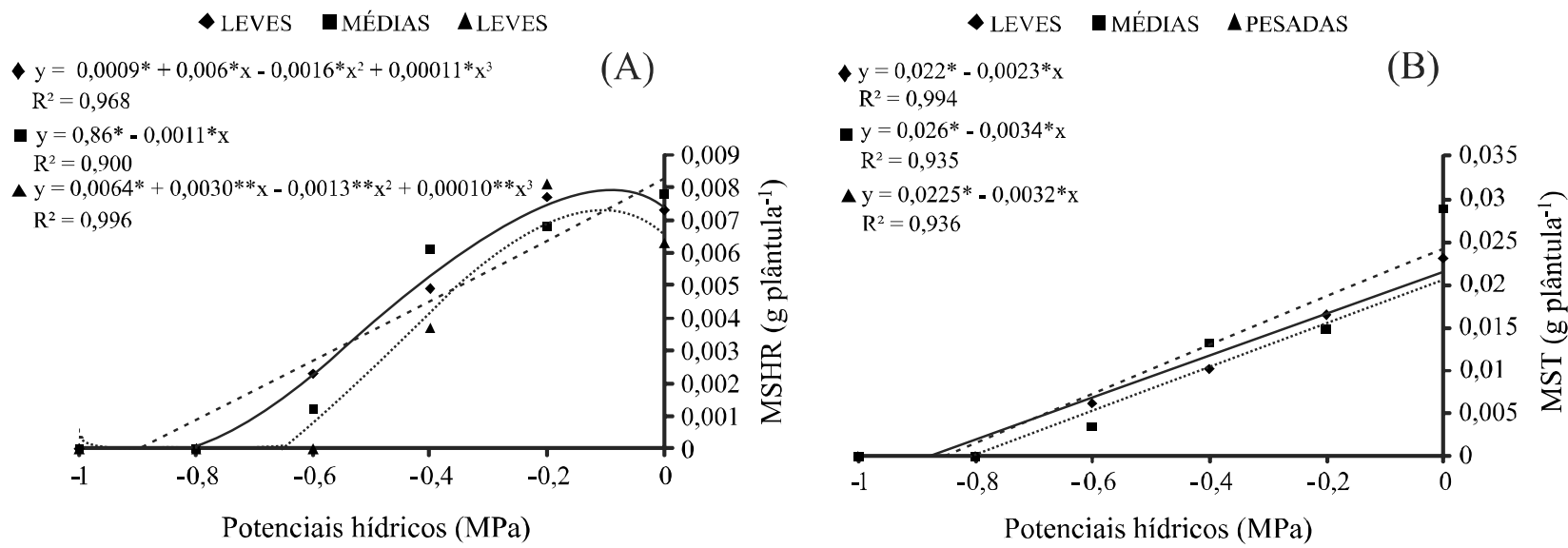
O melhor desempenho para o desenvolvimento da espécie $A$. cearensis em relação a massa das sementes, destacam-se as leves e médias, o que pode estabelecer que estas apresentem maior tolerância às condições de estresse hídrico. Já com relação ao baixo desempenho das sementes pesadas, estas vêm sendo influenciadas desde a etapa da germinação, acarretando alterações no estabelecimento da plântula. No entanto, existem ainda poucas informações disponíveis sobre a influência da massa das sementes nas diferentes condições de estresse hídrico, necessitando assim, de mais estudos.

O decréscimo na absorção de água pelas sementes, principalmente nos níveis mais baixos de potencial hídrico $(-0,6 ;-0,8$ e $-1,0 \mathrm{MPa})$, revelou drástica redução no desempenho germinativo e no crescimento de plântulas de cumaru. Com os resultados obtidos, pode-se observar que as três classes de massa de sementes são sensíveis ao déficit hídrico, o que limita não só o desempenho germinativo, mas também o desenvolvimento da plântula. Embora a espécie seja nativa da caatinga, estas não toleram um gradiente hídrico muito baixo, necessitando assim, estabelecer estratégias agronômicas favoráveis à propagação dessa espécie frente às condições hídricas necessárias para o seu desenvolvimento, levando em consideração o melhor estágio de formação das mudas com sistema radicular bem formada, capazes de superar o estresse hídrico por mais tempo.

\section{CONCLUSÕES}

1.O decréscimo do potencial hídrico do substrato prejudica a germinação e o crescimento de plântulas A. cearensis oriundas de sementes médias e pesadas em comparação às leves;

2.O potencial hídrico a partir do nível -0,6 MPa torna-se uma condição limitante na germinação e formação de plântulas normais de A. cearensis.

\section{REFERÊNCIAS}

ALVES, M. M. et al. Potencial fisiológico de sementes de Clitoria fairchildiana R. A. Howard. - Fabaceae submetidas a diferentes regimes de luz e temperatura. Ciência Rural, v. 42, n. 12, p. 2199-2205, 2012.

AVILA, M. R. et al. Influência do estresse hídrico simulado com manitol na germinação de sementes e crescimento de plântulas de canola. Revista Brasileira de Sementes, v. 29, n. 1, p. 98106, 2007.

AZERÊDO, G. A. Qualidade fisiológica de sementes de Piptadenia moniliformis Benth. 2009. 121 f. Tese
(Doutorado em Agronomia) - Universidade Estadual Paulista, Jaboticabal, 2009.

BARBOSA, D. C. A. Estratégias de germinação e crescimento de espécies lenhosas da caatinga com germinação rápida. In: LEAL, I. R.; TABARELLI, M.; SILVA, J. M. C. (Ed.). Ecologia e conservação da caatinga. Recife: Universidade Federal de Pernambuco, 2003. p. 625-656.

BELLO, E. P. B. C. S. et al. Germinação de sementes de Amburana acreana (Ducke) submetidas a diferentes condições de temperatura e de estresse hídrico. Revista Brasileira de Sementes, v. 30, n. 3, p. 16-24, 2008.

BEWLEY, J. D.; BLACK, M. Seeds: physiology of development and germination. New York and London: Plenum Press, 1994. 445 p.

BORGHETTI, F.; FERREIRA, A. G. Interpretação de resultados de germinação. In: FERREIRA, A. G.; BORGHETTI, F. (Org.). Germinação: do básico ao aplicado. Porto Alegre: Artmed, 2004. p. 209-222.

BRACCINI, A. L. et al. Germinação e vigor de sementes de soja sob estresse hídrico induzido por soluções de cloreto de sódio, manitol e polietileno glicol. Revista Brasileira de Sementes, v. 18, n. 2, p. 10-16, 1996.

BRASIL. Ministério da Agricultura e Reforma Agrária. Regras para análises de sementes. Brasil: SNDA/DNDV/ CLAV, 2009. 399 p.

CANUTO, K. M. et al. Uso de plantas jovens de Amburana cearensis A. C.Smith: Alternativa para preservação e exploração econômica da espécie. Embrapa Semiárido, Petrolina, 2008. 24 p. (Documentos, 208).

CARVALHO, N. M.; NAKAGAWA, J. Sementes: ciência, tecnologia e produção. 5. ed. Jaboticabal: FUNEP, 2012. 590 p.

GHOLZ, H. L.; EWEL, K. C.; TESKEY, R. O. Water and forest productivity. Forest Ecological Management, v. 30, n. 1, p. 1-18, 1990.

GUEDES, R. S. et al. germinação e vigor de sementes de Apeiba tibourbou submetidas ao estresse hídrico e diferentes temperaturas. Ciência Florestal, v. 23, n. 1, p. 45-53, 2013.

HARPER, J. L.; BENTON, R. A. The behaviour of seeds in soil: II. The germination of seeds on the surface of a water supplying substrate. Journal of Ecology, v. 54, n. 1, p. 151-166, 1966.

LESSA, B. F. T. Germinação e crescimento de plântulas de Enterolobium contorsiliquum (vell.) morong em função do peso de semente, localização no fruto e condições de temperatura e luz. 2013. 60 f. Dissertação (Mestrado em Agronomia) - Universidade Federal do Ceará, Fortaleza, 2013.

LORENZI, H. Árvores Brasileiras: manual de identificação e cultivo de plantas arbóreas nativas do Brasil. 5. ed. Nova Odessa: Instituto Plantarum, 2008. 384 p. v. 1.

NAKAGAWA, J. Teste de vigor baseados no desempenho de plântulas. In: KRZYZANOWKI, F. C.; VIEIRA, R. D.; FRANÇA NETO, J. B. (Eds.). Vigor de sementes: conceitos e testes. Londrina: ABRATES, 1999. p. 1-21. 
MARCOS FILHO, J. Fisiologia de sementes de plantas cultivadas. Piracicaba: FEALQ, 2005. 495 p.

PELEGRINI, L. L. et al. Efeito do estresse hídrico simulado com NaCl, manitol e PEG (6000) na germinação de sementes de Erythrina falcata Benth. Ciência Florestal, v. 23, n. 2, p. 511-519, 2013.

PEREIRA, S. R. et al. Tamanho de frutos e de sementes e sua influência na germinação de jatobá-do-cerrado (Hymenaea stigonocarpa var. stigonocarpa Mart. ex Hayne, Leguminosae - Caesalpinoideae. Revista Brasileira de Sementes, v. 33, n. 1, p. 141-148, 2011.

REGO, S. S. et al. Estresse hídrico e salino na germinação de sementes de Anadenanthera colubrina (Veloso) Brenan. Journal of Biotechnology and Biodiversity, v. 2, n. 4, p. 37-42, 2011.

RIBEIRO, C. A. D. et al. Fatores que afetam a germinação das sementes e a biomassa de plântulas de Tabebuia heptaphylla. Revista Floresta, v. 42, n. 1, p. 161-168, 2012.

SOUZA, G. M.; CARDOSO, V. J. M. Effects of diferente environmental stress on seed germinaton. Seed Science and Technology, v. 28, p. 621-630, 2000.
STEFANELLO, R. et al. Influência da luz, temperatura e estresse hídrico na germinação e no vigor de sementes de anis. Revista Brasileira de Agrociência, v. 12, n. 1, p. 4550, 2006 .

TAIZ, L.; ZEIGER, E. Fisiologia vegetal. 4. ed. Porto Alegre: Artmed, 2009. 722 p.

TÁVVORA, F. J. A. F.; MELO, F. I. Respostas de cultivares de amendoim a ciclos de deficiência hídrica: Crescimento vegetativo, reprodutivo e relações hídricas. Ciência Agronômica, v. 22, n. 1, p. 47-60, 1991.

TAYLOR, A. G.; HARMAN, G. E. Concepts and technologies of selected seed treatments. Annual Review Phytopathlogy, v. 28, p. 321-339, 1990.

TROVÃO, D. M. B. M. et al. Variações sazonais de aspectos fisiológicos de espécies da Caatinga. Revista Brasileira de Engenharia Agrícola e Ambiental, v. 11, n. 3, p. 307-311, 2007.

VILLELA, F. A.; DONI FILHO, L.; SIQUEIRA, E. L. Tabela do potencial osmótico em função da concentração de polietileno glicol 6000 e da temperatura. Pesquisa Agropecuária Brasileira, v. 26, n. 11/12, p. 1957-1968, 1991. 